\title{
Anaerobes: a new aetiology in cavitary pneumoconiosis
}

\author{
J M DEL CAMPO, J HITADO, G GEA, A COLMEIRO, A M LANZA, J A MUÑOZ, AND \\ J A MOSQUERA
}

From the National Silicosis Institute, Oviedo, Spain

\begin{abstract}
The role of mycobacteria in the cavitation of large pneumoconiotic masses is well established. In other cases softness is attributed to an ischaemic or aseptic necrosis. Five cases are described in which cavitation of the pulmonary masses was caused by anaerobic bacteria, confirmed by the growth of such bacteria in cultures after transtracheal or transpleural puncture. Repeated cultures for mycobacteria gave negative results. Two cases were acute, having serious complications such as bronchopleural fistula, empyema, and serious respiratory insufficiency. The role of anaerobes in cavitary pneumoconiosis has not been recognised previously, probably because of the special conditions required to culture these bacteria and the infrequent use of transtracheal puncture in the diagnosis of this entity. The prevalence of anaerobes as agents capable of cavitating pneumoconiotic masses remains to be established.
\end{abstract}

Complicated pneumoconiosis is characterised by the presence of pulmonary masses exceeding $1 \mathrm{~cm}$ in diameter. Cavitation is a complication of these large masses. The importance of mycobacteria as a cause of cavitation has long been recognised, ${ }^{1}$ other suggested factors being ischaemic or aseptic necrosis. ${ }^{2}$ In this paper we descibe for the first time the role of anaerobes in the cavitation process of conglomerate masses in the lungs of coal miners.

\section{Material and methods}

All the patients studied had worked in coal mining and had not been treated with antibiotics for at least 72 hours before the bacteriological studies were performed. $X$-ray findings were evaluated by two independent readers using the Cincinnnati Classification. ${ }^{3}$ The patient was considered to have large masses of progressive massive fibrosis if the following criteria were present: (1) abnormal shadows exceeding $1 \mathrm{~cm}$ across, (2) diffuse micronodular infiltration, and (3) a history of industrial exposure to dust. Pleural puncture was performed by a standard technique. ${ }^{4}$ Transtracheal puncture was performed by passing a polyethylene catheter

Received 10 September 1981

Accepted 4 January 1982 through a No 16 needle inserted into the cricothyroid membrane. ${ }^{5}$ Samples were obtained by aspiration or by washing out with bicarbonated serum, ${ }^{6}$ and the material was promptly sent for culture in media suitable for anaerobes such as fungi and mycobacteria. The media used for anaerobe identification were:

(1) Primary isolation in: (a) Brucella Agar (BBL 11086) supplemented with Hemin $(5 \mu \mathrm{g} / \mathrm{ml})$; vita$\min \mathrm{K}_{1}(10 \mu \mathrm{g} / \mathrm{ml})$ and $5 \%$ sheep blood; (b) Thioglycollate broth (BBL 11720-135 C) supplemented with Hemin $(5 \mu \mathrm{g} / \mathrm{ml}) \mathrm{Ca} \mathrm{CO}_{3}$ chip, $5 \%$ Filles extract (Difco), vitamin $\mathrm{K}_{1}(0 \cdot 1 \mu \mathrm{g} / \mathrm{ml})$ and $\mathrm{Na}$ $\mathrm{HCO}_{3}(1 \mu \mathrm{g} / \mathrm{ml})$; (c) Blood Agar Plate (Tryptic Soy Agar Difco with 5\% sheep blood); (d) kanamycin vancomycin laked blood Agar (brain heart infusion Agar Difco; Hemin $(5 \mu \mathrm{g} / \mathrm{ml})$, vitamin $\mathrm{K}_{1}(10 \mu \mathrm{g} /$ $\mathrm{ml})$, kanamycin $(100 \mu \mathrm{g} / \mathrm{ml})$, vancomycin $(7.5 \mu \mathrm{g} /$ $\mathrm{ml}$ ), and 5\% laked sheep blood).

The brucella agar, the kanamycin-vancomycin laked blood Agar plate, and the thioglycollate broth were incubated in an anaerobic jar (Gas Pak BBL), at $35-37^{\circ} \mathrm{C}$ for 48 hours. Two blood agar plates were incubated, in air and $10 \% \mathrm{CO}_{2}$ respectively, at $37^{\circ} \mathrm{C}$ for 24 hours.

(2) The identification of the anaerobic organisms was made following the Wadsworth anaerobic bacteriology manual (2nd ed, 1975) ${ }^{78}$ and the Mayo Clinic bacteriology manual 1st ed, 1978. 


\section{Clinical observations}

\section{CASE 1}

A 52-year-old man who had worked as a coal miner for nine years (1949-58) after working five as a face worker was diagnosed in 1963 as having pneumoconiosis, category B. The patient had been drinking one litre of wine and four glasses of spirits a day for 36 years.

He was in hospital because of constitutional symptoms, cough, purulent sputum, and dyspnoea during the past three months. Five days before entering hospital he complained of right pleuritic pain, melanoptysis, and a temperature of $38^{\circ} \mathrm{C}$.

Examination showed labial herpes, teeth in poor condition, crackles, and bronchophony in the right axilla. Temperature was $39^{\circ} \mathrm{C}$ and the Mantoux test result was negative with $250 \mathrm{IU}$ of purified protein derivative (PPD). There was polymorphonuclear leucocytosis $\left(15.9 \times 10^{9} / 1\right)$. Erythrocyte sedimentation rate early in the morning was $111 \mathrm{~mm} / \mathrm{h}$. Five Ziehl-Neelsen sputum smears and sputum cultures in Lowenstein-Jensen medium gave negative results.

Bilaterally cavitated masses were seen in the chest radiograph and in tomograms (fig 1 ).

Peptostreptoccoci sensitive to penicillin and clindamycin were cultured from the transtracheal specimen. The patient was treated with these antibiotics at a dosage of $8 \times 10^{6} \mathrm{U} /$ day and $1200 \mathrm{mg} /$ day respectively with pronounced clinical improvement but persistence of the cavities.

\section{CASE 2}

A 57-year-old coal miner who had been a driller for 14 years was diagnosed as having complicated

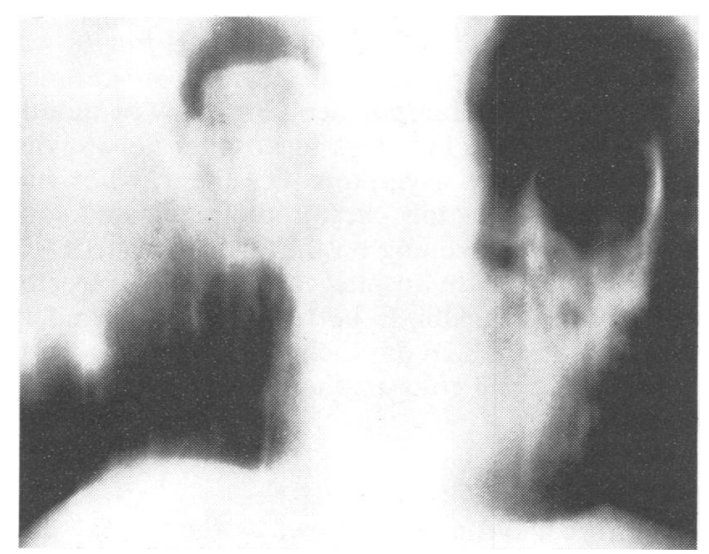

Fig 1 Case 1: Tomogram of lung in which bilaterally cavitated pneumoconiotic masses are seen. Right cavity is irregular and anfractuous. pneumoconiosis with category $\mathrm{C}$ masses. He had had a chronic cough for the past 15 years and was in hospital because of a history of coughing, dyspnoea, and melanoptysis for two weeks. The only notable finding on examination was bronchophony in the upper third of the back of the right hemithorax. Temperature was $37.6^{\circ} \mathrm{C}$ and the Mantoux test result was $12 \mathrm{~mm}$ in diameter with 1 IU of PPD.

Haemoglobin was $12 \mathrm{~g} / \mathrm{dl}$, leucocytes $8.7 \times 10 \% 1$. The ESR early in the morning was $96 \mathrm{~mm} / \mathrm{h}$. Five Ziehl-Neelsen smears of sputum and three cultures in Lowenstein-Jensen medium gave negative results. The chest radiograph showed cavitation with fluid level in the right upper lobe (fig 2).

Bacteroides melaninogenicus and peptostreptococci sensitive to clindamycin were grown from the transtracheal culture. The patient was treated with clindamycin, $500 \mathrm{mg}$ every six hours for three weeks. His condition improved and the melanoptysis and the fluid level disappeared.

\section{CASE 3}

This 45-year-old man who was a non-smoker and did not drink alcohol had received treatment for grand mal epilepsy since he was 15 . He had worked in coal mines for eight years as a shorer, two years as a tub operator, and one year as a face worker. Diagnosed in 1967 as having complicated pneumoconiosis, category $\mathrm{C}$, and suspected of pulmonary tuberculosis, without bacteriological confirmation, he was given antituberculous chemotherapy for three years.

Ten days after his admission to hospital (June 1980) because of melanoptysis and haemoptysis, his

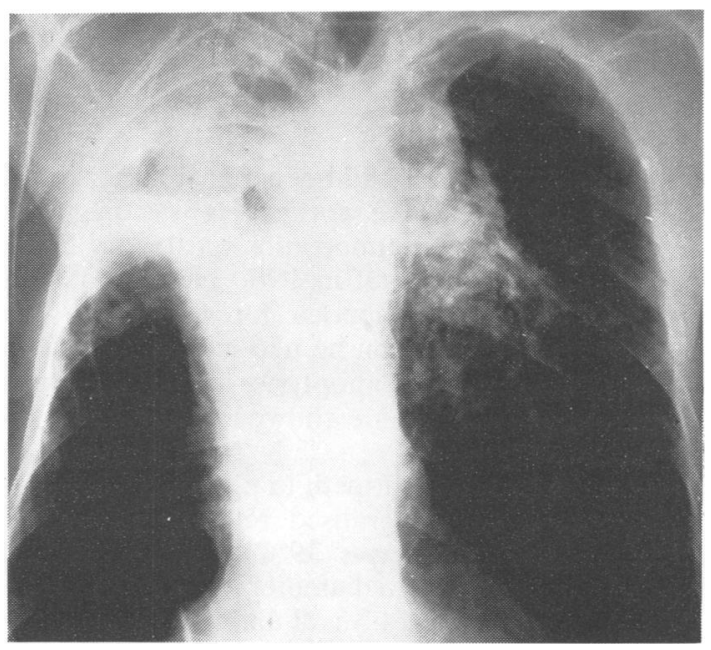

Fig 2 Case 2: Note cavitation with ftuid level in right upper lobe. 


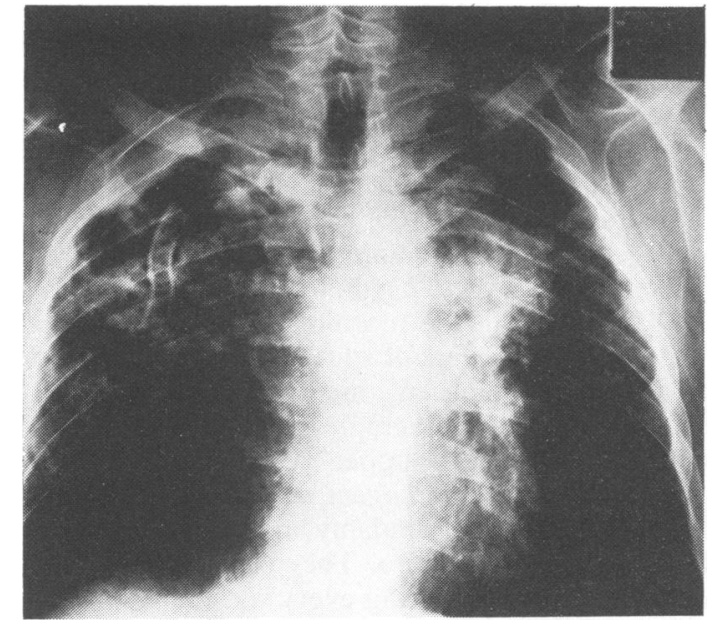

Fig 3 Case 3: Cavitated mass in right upper lobe with intercavitary drainage tube.

temperature was $40^{\circ} \mathrm{C}$; four days later right pleuritic pain appeared with friction at the same level. Haemoglobin was $16.7 \mathrm{~g} / \mathrm{dl}$, leucocytes $12.4 \times 10^{9} /$. Repeated examination of sputum and pleural fluid, including three cultures in Lowenstein-Jensen medium, failed to show any mycobacteria.

A chest radiograph showed cavitation of the masses in the right upper lobe and obliteration of the costodiaphragmatic sinus on the same side. Purulent fluid was obtained by thoracentesis. Peptostreptococci and $B$ fragilis grew in its culture. Treatment was started with penicillin at a dosage of $20 \times 10^{6}$ $\mathrm{U} /$ day, and clindamycin $1.5 \mathrm{~g} /$ day for 23 days with good clinical response, but with persistence of a bronchopleural fistula and the cavitation until now, 10 months after admission to hospital (fig 3 ).

\section{CASE 4}

This 53-year-old man had been a coal miner for 32 years, 27 years as a face worker. He was diagnosed in 1969 as having pneumoconiosis, category B and was admitted to hospital in 1980 because of right pleuritic pain and dyspnoea for five days. Two months before admission he had had constitutional symptoms-cough, melanoptysis, and haemoptysis. Radiography at that time showed cavitation in the right upper mass.

Examination showed teeth in poor condition, putrid sputum, and generalised reduction of breath sounds. Temperature was $39^{\circ} \mathrm{C}$ and the Mantoux test result was $11 \mathrm{~mm}$ in diameter with $1 \mathrm{IU}$ of PPD.

Haemoglobin was $14.3 \mathrm{~g} / \mathrm{dl}$ and leucocytes $9.2 \times$ $10^{\circ} /$. ESR early in the morning was $116 \mathrm{~mm} / \mathrm{h}$. Five Ziehl-Neelsen smears of sputum and three cultures

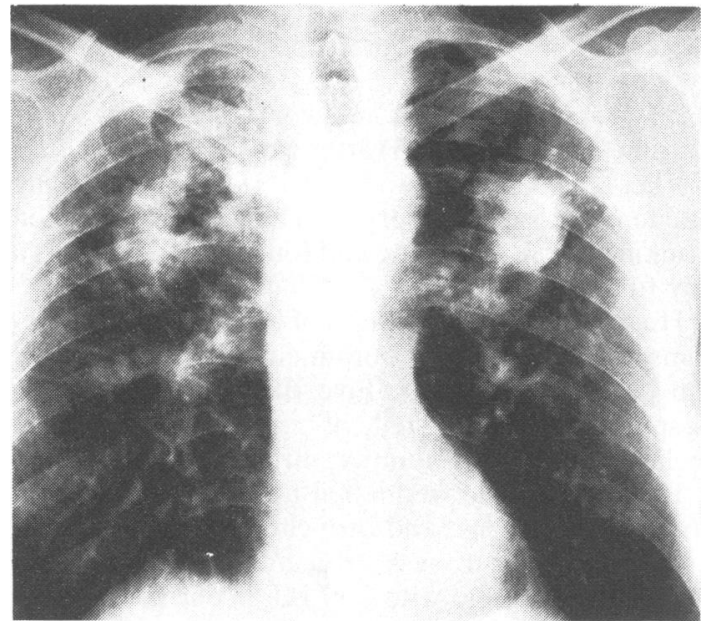

Fig 4 Case 4: Cavitated mass in right upper lobe.

in Lowenstein-Jensen medium gave negative results.

The chest radiograph showed increased cavitation of the mass in the right upper lobe (fig 4). A transtracheal puncture was performed and bacteroides strains sensitive to penicillin, clindamycin, and chloramphenicol were grown from the aspirate. Treatment was started with penicillin 12 million U/day. Five days later the patient's condition deteriorated and the radiograph showed multiple fluid levels in the right upper lobe. The patient required mechanical ventilation for six days, with the addition of clindamycin $1.5 \mathrm{~g}$ every 24 hours which had to be discontinued five days later because of diarrhoea. Thirty days after admission to hospital the radiograph showed right pleural effusion from which a foul smelling fluid containing $B$ fragilis was obtained. The empyema was treated with thoracic drainage, and chloramphenicol, $3 \mathrm{~g}$ a day by mouth, was added. After 115 days in hospital he was discharged clinically asymptomatic, the cavities had disappeared from the chest radiograph, and only slight pleural thickening on the right persisted.

During his stay in hospital the patient was treated with sodium penicillin $G$ between $12 \times 10^{6}$ and 18 $\times 10^{6} \mathrm{U} /$ day for 110 days, clindamycin $1.5 \mathrm{~g}$ a day for five days, and chloramphenicol $3 \mathrm{~g}$ a day for 53 days.

\section{CASE 5}

This 79-year-old man who had worked at the coal face for 24 years was diagnosed in 1950 as having complicated pneumoconiosis, category C. He had had a chronic cough for 30 years and progressive 
dyspnoea for 12 . He was admitted to hospital because of the development during a one-week period of increased dyspnoea, cough, melanoptysis, and irregular pyrexia up to $39^{\circ} \mathrm{C}$.

Examination showed a global reduction of breath sounds and basal wheezing. Temperature on admission was $38.8^{\circ} \mathrm{C}$ and the Mantoux test result was negative with 1 IU of PPD. Haemoglobin was 14.4 $\mathrm{g} / \mathrm{dl}$, leucocytes $14.2 \times 10^{9} /$. ESR early in the morning was $80 \mathrm{~mm} / \mathrm{h}$. Four Ziehl-Neelsen smears of sputum and a culture in Lowenstein-Jensen medium gave negative results. The chest radiograph showed no change in category $\mathrm{C}$ massive fibrosis. On the eighth day in hospital the sputum became putrid and the chest radiograph showed cavitation with fluid level in the fibrotic mass on the left side. A transtracheal puncture was performed and peptostreptococci, $B$ fragilis, $B$ melaninogenicus, and Escherichia coli grew in culture of the aspirate. $B$ fragilis grew in blood cultures. The patient was treated with chloramphenicol (4 g/day) associated with metronidazole $(1.5 \mathrm{~g} /$ day $)$. Progress was satisfactory with clearing of the sputum and disappearance of the fever. The mass and its cavity diminished notably after treatment.

\section{Discussion}

Sufficient exposure to a dusty atmosphere may lead to the appearance of micronodular pneumoconiosis that does not produce problems. Out of our miners, $13.9 \%{ }^{9}$ acquired large masses, one complication of which is cavitation. It has been recognised that mycobacteria can cause cavitation. ${ }^{10}$ In the remaining cases the search for bacteria has generally been fruitless. It was thought that liquefaction of the masses was caused by ischaemic or aseptic necrosis, ${ }^{11}$ for which no treatment was required. Five cases are described in which sputum culture for mycobacteria was negative, but cavitation of the pulmonary masses was accompanied by infection with anaerobic bacteria. One patient developed respiratory failure, two had empyema, and all responded to antibiotics. When massive fibrosis is complicated by infection, whether tuberculous or anaerobic, prompt and appropriate treatment is required.

The role of anaerobes as necrotising agents of pulmonary tissue is well known, and increasingly recognised..$^{12-14}$ In this area necrotising pneumonias and empyemas caused by anaerobes are often encountered in coal miners. When they have pneumoconiosis the resultant bronchial distortion, or ischaemia of fibrotic masses, favours the growth of these micro-organisms. In our patients the role of aspiration of mouth anaerobes had an important role as the likely source of infection: two had dental sepsis, one drank regularly, and one was an epileptic. Only occasionally have others reported the formation of abscesses in the conglomerate masses by non-mycobacterial organisms. ${ }^{15} 16$ In 1961 Balgairies and Macquet ${ }^{17}$ described 14 cases of pleuropulmonary suppuration in patients with pneumoconiosis, in three of which cavitation of the masses occurred. One of their cases had putrid sputum but the cultures were sterile. In the other two cases Staphylococcus aureus and Streptococcus pneumoniae were found. ${ }^{17}$ We have reviewed reports, the Index Medicus, and Excerpta Medica since 1955 as well as 20 monographs on pneumoconiosis without having found any work that shows the role of anaerobes in the cavitation of the masses in progressive massive fibrosis.

There are two reasons why they have been overlooked. Firstly, because the technical difficulties of cultivating these micro-organisms has caused them to be practically forgotten ${ }^{18}$ despite the fact that they were the first to be described by Pasteur, and their pathogenic role was recognised in the last century. The simplification and standardisation of culture methods in recent years has permitted their rediscovery. Secondly, transtracheal puncture, by preventing contamination in the oropharynx, has played an important part in improving the identification of the micro-organisms responsible for pulmonary lesions. ${ }^{1920}$

We conclude that anaerobes should be considered as one of the factors that cause cavitated pneumoconiosis, but that their prevalence must be determined in future studies.

\section{References}

' Parkes WR. Occupational lung disorders. London: Butterworths Co, 1974:217.

${ }^{2}$ XV Journees Nationales de Medicine du Travail. Strasbourg (10-13 Mai 1978). Archives des Maladies Professionnelles de Medicine du Travail et de Securité Sociale 1979;40:35-6.

${ }^{3} \mathrm{UICC} / \mathrm{Cincinnati}$ classification of the radiographic appearances of pneumoconioses: a cooperative study by the UICC committee. Chest 1970;58:57-62.

4 Fishman AP. Pulmonary diseases and disorders. New York: McGraw-Hill Book Co, 1980:136.

s Bartlett JG, Rosenblatt JE, Finegold SM. Percutaneus transtracheal aspiration in the diagnosis of anaerobic pulmonary infection. Ann Intern Med 1973;79:535-8.

- Bartlett JG. Diagnostic accuracy of transtracheal aspiration bacteriologic studies. Am Rev Respir Dis 1977;115:777-82.

${ }^{7}$ Rosenblatt JE. Isolation and identification of anaerobic bacteria. Hum Pathol 1976;7:177-9.

- Natsen JM, Ederer GM. Specimen collection and transport. Hum Pathol 1976;7:297-9.

9 Muñoz Martinez JA, Sala Felis JL, Mendez Lanza A, Cabezudo Hernandez MA, Carretero Sastre JL, Mosquera JA. Neumoconiosis complicada. Archivos de Bronconeumología 1978;14:175-8. 
${ }^{10}$ Reginster A. Formes necrotiques de l'antracosillcose et silicotuberculose. Rev Med Liege 1960;15:729-36.

"Carpathios J. Cavitary silicosis. Am Rev Respir Dis $1961 ; 84: 84-6$.

${ }^{12}$ Bartlett JG, Finegold SM. Anaerobic infections of the lung and pleural space. Am Rev Respir Dis 1974;110:56-75.

${ }^{13}$ Bartlett JG. Anaerobic bacterial pneumonitis. Am Rev Respir Dis 1979:119:19-23.

${ }_{14}$ Escribano D, Alvarez C, Roman A. Infecciones pulmonares por anaerobios: a proposito de 11 casos. Archivos de Bronconeumología 1979;15:4-6.

${ }^{15}$ Cohen L, Grunwald E, Perret A. Abces du poumon chez le silicotique. Revue Lyonnaise de Medecine 1959;8:1411-4.

${ }^{16}$ Marin A, Reynaud CA, Vitani C. Les images cavitaires de la silicose pulmonaire. La Revue du Praticien 1960;10:71-81.

${ }^{17}$ Balgairies E, Macquet V. Supuration pleuro-pulmonaires chez les pneumoconiotiques. Lille Med 1961;6:62-8.

${ }^{18}$ Gernez-Rieux C, Tacquet A, Voisin C, Decalder B. Le role des infections dans le pathogenie des fibrosis massives progressives des mineurs de Charbon. Med Lab 1965;56:500-16.

${ }^{19}$ Finegold SM, Bartlett JG, Chow AW. Management of anaerobic infections. Ann Intern Med 1975;83:375-89.

${ }^{20}$ Bartlett JG. Diagnostic accuracy of transtracheal aspiration bacteriologic studies. Am Rev Respir Dis 1977;115:777-81. 